\title{
THE IMPACT OF HYDRAULIC SYSTEMS ON THE HUMAN BEING AND THE ENVIRONMENT
}

\author{
Michat Stosiak \\ Wrockaw University of Technology, Department of Hydraulic Machines and Systems, Wroclaw, Poland \\ e-mail: michal.stosiak@pwr.wroc.pl
}

\begin{abstract}
Some hazards posed by the operation of hydraulic systems, connected with low-frequency vibrations and noise are presented. Special attention is focused on infrasounds. The sources of low-frequency vibrations and noise and the ways of reducing them are indicated. Moreover, this paper deals with the effects of external mechanical vibrations on hydraulic valves. An original solution ensuring the effective reduction of vibrations and noise in a wide frequency range, i.e. a wide-band damper of pressure fluctuations, also performing the function of an acoustic filter, is proposed. The results of preliminary experimental tests of simple vibration insulators are reported. The effectiveness of the damper has been confirmed by the results of laboratory tests and tests carried out on engineering machines working in real conditions.Problems relating to the noise emitted into the environment by machines equipped with hydraulic systems are covered by Polish and EU standards and directives, e.g. PN-ISO 9612:2004, Directive No. 2000/14/EC and Directive No. 98/37/WE.
\end{abstract}

Keywords: hydraulic systems, vibrations, noise

\section{Introduction}

This paper deals with the reduction of vibrations and noise emitted by heavy engineering machines, generally with long-frequency noise and, specifically, with infrasonic noise (Kaczmarska et al., 2006). Infrasounds are commonly defined as sounds or noise whose frequency spectrum is in a range of 1 to $20 \mathrm{~Hz}$. Currently, the concept of low-frequency noise covering the frequency range from about $10 \mathrm{~Hz}$ to about $250 \mathrm{~Hz}$ is increasingly widely used. The lower frequency limit $(10 \mathrm{~Hz})$ has been adopted due to considerable difficulties in measuring this noise correctly and interpreting the results for frequencies below 8-10 Hz. Low-frequency noise, including infrasonic noise, is received by the human being through both the auditory canal and the vibration receptors distributed over the whole body. Its harmful impact manifests itself in subjectively perceived excessive fatigue, discomfort, drowsiness, balance and psychomotor disturbances as well as disturbances in the physiological functions. Such states result in changes in the central nervous system, characteristic for diminished wakefulness, which is especially dangerous for operators of machines and equipment (Kaczmarska et al., 2006). Table 1 presents a list of disease symptoms observed for infrasound impact on the human body.

The infrasonic noise problem was noticed only in the recent years and the methods of measuring quantities characterizing infrasonic noise were defined in an ultrasonic noise testing procedure published by Pawlaczyk-Łuszczyńska et al. (2001) and in the standards: PN-ISO 7196:2002 [28] and PN-ISO 9612:2004 [29]. The highest permissible infrasonic noise levels (HPNL values) in the engineering machine operator workplace were specified in the Labour and Social Policy Minister ordinance at the end of 2002 [24]. The noise problem is more extensively dealt with in EU documents. The requirements concerning the noise emitted into the environment by machines have been covered by two new approach directives. The first main directive on machinery noise bears the number 98/37/WE (Directive 98/37/WE, 1988). The second directive is desi- 
Table 1. List of disease symptoms observed for subject to infrasound impact the human body

\begin{tabular}{|c|c|c|c|c|c|}
\hline$f[\mathrm{~Hz}]$ & $L_{m}[\mathrm{~dB}]$ & $t_{\exp }[\mathrm{min}]$ & $N$ & Disease symptoms & Source \\
\hline $2-15$ & 105 & & & $\begin{array}{l}\text { visual reaction time lengthening in } 50 \% \\
\text { of tested persons, balance disturbances in } \\
10 \% \text { of tested persons }\end{array}$ & $\begin{array}{l}\text { (Bryan, } \\
1972)\end{array}$ \\
\hline $1-2$ & 150 & & & $\begin{array}{l}\text { shift in auditory threshold, shifting ear- } \\
\text { drums sensation }\end{array}$ & $\begin{array}{l}\text { (Bryan, } \\
1972)\end{array}$ \\
\hline $2-15$ & $110-120$ & & 7 & reaction time lengthening by $4 \%$ & $\begin{array}{l}\text { (Leventhall, } \\
1973)\end{array}$ \\
\hline $3-15$ & 115 & 30 & & alcohol abuse symptoms & $\begin{array}{l}\text { (Leventhall, } \\
1973)\end{array}$ \\
\hline 10 & 135 & 15 & 6 & $\begin{array}{l}\text { sensation of internal organs vibration, fe- } \\
\text { eling tympanic membrane vibrate, middle } \\
\text { ear ache, rapid pulse, increased arterial } \\
\text { blood pressure, respiration rate increased } \\
\text { by } 4 \text { or more breaths per minute, auditory } \\
\text { threshold shifted by } 15-20 \mathrm{~dB} \text { during test } \\
\text { and by } 8-10 \mathrm{~dB} \text { after test }\end{array}$ & $\begin{array}{l}\text { (Malsev, } \\
1974)\end{array}$ \\
\hline 7 & 90 & 35 & 30 & $\begin{array}{l}\text { drop in blood pressure, lowered pulse rate, } \\
\text { cardiac murmurs occurred in half of tested } \\
\text { persons }\end{array}$ & $\begin{array}{l}\text { (Renowski, } \\
1988)\end{array}$ \\
\hline $2-22$ & $119-144$ & 3 & 30 & $\begin{array}{l}\text { auditory threshold shifted by } 10 \mathrm{~dB} \text { in } 30 \% \\
\text { of tested persons }\end{array}$ & $\begin{array}{l}\text { (Renowski, } \\
1988)\end{array}$ \\
\hline $1-100$ & 154 & $0.4-2.0$ & & $\begin{array}{l}\text { sensation of swaying walls, headache and } \\
\text { dizziness, breathlessness, ear buzzing, loc- } \\
\text { kjaw }\end{array}$ & $\begin{array}{l}\text { (Renowski, } \\
1988)\end{array}$ \\
\hline
\end{tabular}

Legend: $f$ - frequency, $L_{m}$ - acoustic pressure level, $t_{\text {exp }}$ - exposure time, $N$ - number of tested persons, compiled from Bryan (1972), Renowski (1988), Leventhall (1973), Malsev (1974)

gnated with the number 2000/14/WE (Directive 2000/14/EC, 2000) and deals exclusively with the noise emitted by the equipment working outdoors.

The most frequent cause of vibrations are disturbances connected with motion or operation of the machine, for example when a mobile machine moves on an uneven surface or when the rotating parts are unbalanced during material machining. Another major vibration source are drive units, for example a combustion engine performing a periodic variable-characteristic work cycle (Engel and Zawieska, 2010; Leea et al., 2001). An operating hydraulic system is also a source of mechanical vibrations caused mainly by pressure surges and the periodic operation of the displacement pump. Since the generated vibrations have different frequencies, the paths of their transmission are also different. The irregularities of the surface on which a mobile machine moves cause excitations in a frequency range of $0.5-250 \mathrm{~Hz}$ (Krylov et al., 2010; Pytlik, 2008; Grajnert, 1997). The range includes excitations generated by the driving (combustion) engine and the displacement pump kinematics, manifesting themselves in pressure fluctuations in the machine hydraulic system. The vibrations due to resistance of the flowing air are in a frequency range of $250-16000 \mathrm{~Hz}$ and they are caused by airflow separation from machine components. Also the flow of the working medium in the hydraulic system causes vibration and noise. Sometimes cavitation occurs, generating high-frequency noise. Vibrations generated and transmitted by a machine produce various effects. Mechanical vibrations affect the machine operator. Components of the systems with which the machine is equipped, particularly hydraulic components and systems, are also subject to mechanical vibrations. 
The same requirements and principles as the ones for the audible range $(20 \mathrm{~Hz}-20 \mathrm{kHz})$ noise, e.g. caused by impact pressure variations or by factors connected with working liquid flow (cavitation - cavitation noise is high-frequency noise) are applied in the prevention of the harmful effects of infrasonic noise (Tabaczek et al., 2012; Kollek et al., 2007a). Because of the considerable infrasound wavelengths $(17-340 \mathrm{~m})$, the protection against infrasounds poses difficulty since conventional walls, partitions, screens and sound absorbers are rather ineffective in their case. In some cases, infrasonic waves are amplified due to resonance of rooms, structural elements of cabs and whole constructions. The best protection against the harmful impact of infrasounds is their elimination at the source, i.e. by eliminating the causes of infrasonic noise generation. Moreover, in order to minimize the vibration of the hydraulic valve control element, it seems sensible to isolate the valve housing from the external mechanical vibrations of the base (for example, the vibrating frame of a mobile machine or a machine tool).

\section{Materials and methods}

In real operating conditions, hydraulic valves (also valve blocks) are subjected to mechanical vibrations (Kollek et al., 2008; Pytlik, 2008; Grajnert, 1997). There are different sources of the vibrations such as the unbalance of rotating parts of machines, variable loads, travel on an uneven surface, etc., producing many adverse effects such as vibration of the control elements in hydraulic valves. The elements are responsible for fixing the size of gaps in hydraulic valves. When the valve control element (e.g. the slide) begins vibrating, its throttling gap area changes, which results in output and pressure fluctuations in the hydraulic system. The spectral components of this vibration correspond to the spectral components of the excited element (Stosiak, 2006a). The authors' own research and literature reports (Misra et al., 2002; Kudźma, 1990; Tomasiak, 1983) indicate that the resonance frequencies of valve control elements (conical heads, slides) are below $100 \mathrm{~Hz}$ (Stosiak, 2011, 2006a). This frequency range is particularly dangerous for people since the resonance frequencies of major internal organs are below $100 \mathrm{~Hz}$ (Engel and Zawieska, 2010; Renowski, 1988). The fluctuations may produce infrasounds. Pressure fluctuations may result in unstable operation of hydraulic receivers, contributing to, among other things, their imprecise work.

Tests in which a simulator of the linear hydrostatic drive was used as a source of external low-frequency mechanical vibrations were carried out. The simulator was described in more detail in (Cichoń and Stosiak, 2011; Kollek et al., 2008).

In the test described in this paper, a selected hydraulic valve is mounted in a specially designed grip of the simulator. The valve is then subjected to mechanical vibrations generated by the simulator and the pressure fluctuations in this hydraulic system are recorded by a piezoelectric ICP transducer. The direction of the external mechanical vibrations coincides with the direction of motion of the tested valve control element. A diagram of the hydraulic system in which the selected valve was tested is shown in Fig. 1.

An overall diagram showing the amplitude-frequency spectrum of the pressure fluctuation in the hydraulic system with the vibrating proportional distributor, consistent with Fig. 1a, is shown in Fig. 2.

In Fig. 2 one can see spectral components the frequencies of which correspond to the frequencies of the external mechanical vibrations below $100 \mathrm{~Hz}$. Moreover, there is a component originating from the fluctuations in the delivery of the pump feeding the distributor system. The rotational speed of the pump drive shaft and the number of pump displacement parts indicate that the resulting spectral component will appear at a frequency of about $242 \mathrm{~Hz}$. Figure 3 presents the results of experiments in which a single-stage valve has been placed on the vibrating table of the hydraulic simulator in the hydraulic system shown in Fig. 1b. 

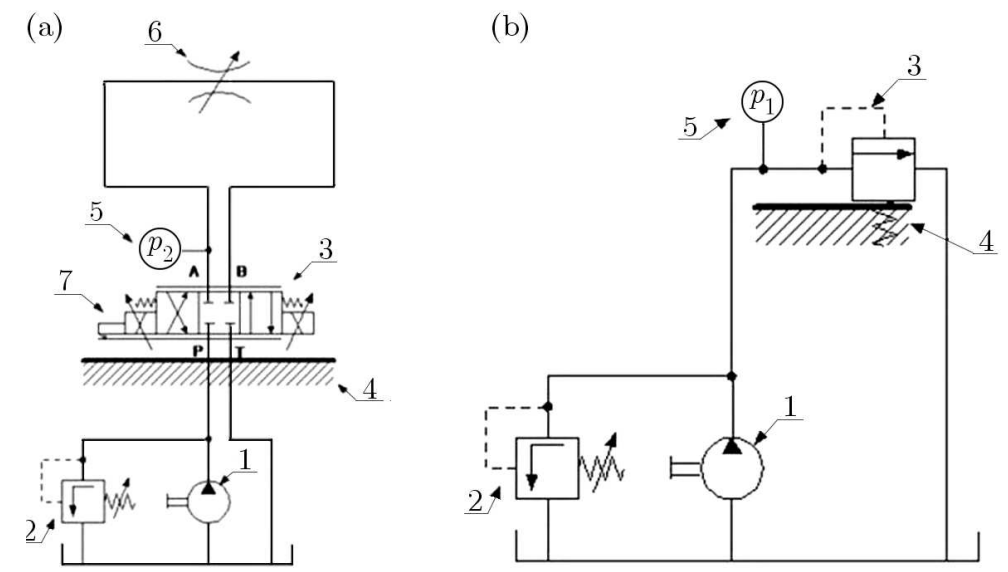

Fig. 1. Diagram of the hydraulic system used for valve testing: 1 - displacement pump, 2 - safety valve, 4 - vibrating simulator table, 5 - pressure measurement, 6 - adjustable throttle valve;

(a) 3 - proportional distributor, 7 - slide displacement sensor, (b) 3 - overflow valve; $p_{2}$ - pressure behind the proportional distributor, between the proportional distributor and adjustable throttle valve, $p_{1}$-pressure before the overflow valve, between pump and the overflow valve

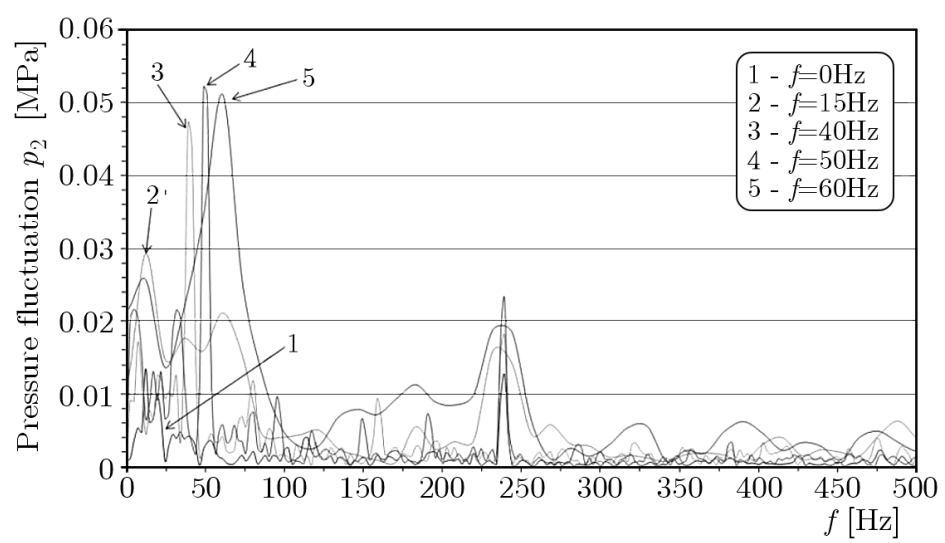

Fig. 2. Spectrum of pressure fluctuation in the hydraulic system with the proportional distributor excited with frequency $f=0,15,40,50$ and $60 \mathrm{~Hz}$. Average pressure $-2 \mathrm{MPa}$, average flow rate $6.5 \mathrm{dm}^{3} / \mathrm{min}$

Analysis of the results presented in Figs. 2 and 3 shows that there is a correlation between some components of the pressure fluctuation spectrum and the external mechanical vibrations acting on the selected hydraulic valves. This manifests itself in the presence of harmonic components corresponding to the frequency of the external mechanical vibrations in the spectrum. The fluctuations, in turn, can excite low-frequency vibrations of the hydraulic conduits, propagating for considerable distances.

In order to minimize the transfer of the external mechanical vibrations from the foundation to the hydraulic valves, one can use, e.g., vibration insulators (Stosiak, 2011). Another effective way of reducing pressure fluctuations at both low frequencies $(<100 \mathrm{~Hz})$ and higher frequencies $(150-350 \mathrm{~Hz})$ is to additionally use a compact pressure fluctuation damper (Kollek et al., 2007b).

\section{Identification of noise sources in the hydraulic system}

Indirectly generated noise dominates in the hydraulic system. Variable forces acting on the parts of the hydraulic system are produced as a result of pressure fluctuations and the mechanical connection of the hydraulic system components through the conduits and the common mounting. 


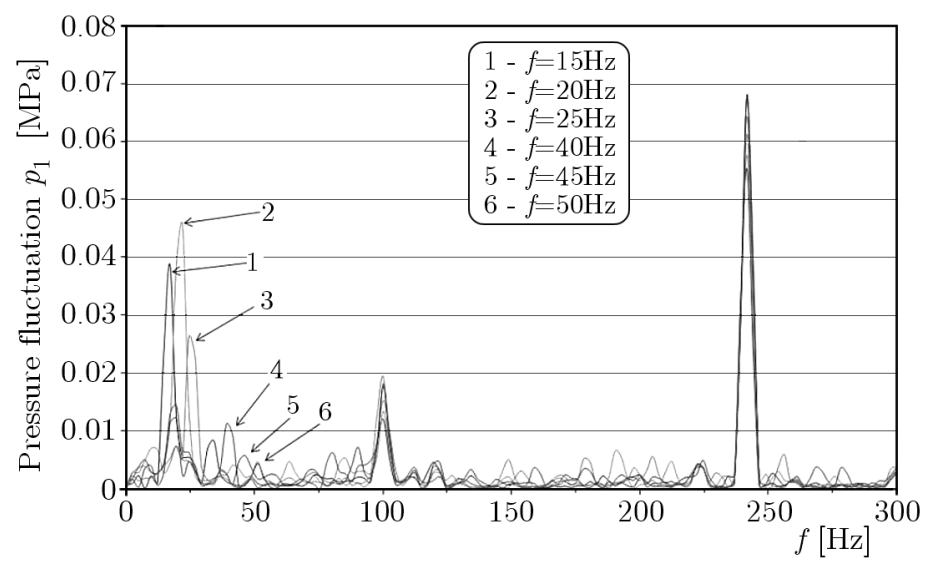

Fig. 3. Spectrum of pressure fluctuation in the hydraulic system with a single-stage overflow valve excited with frequency $f=15,20,25,40,45$ and $50 \mathrm{~Hz}$. Average pressure - $2 \mathrm{MPa}$, average flow rate $6.5 \mathrm{dm}^{3} / \mathrm{min}$

The vibration of a single component, e.g. a valve, is produced by the impact of the liquid and induces vibrations in other elements connected with this component.

Another source of pressure fluctuations in the hydraulic system is the variable character of hydraulic engine loads as well as the engine starting-off and braking (nonstationary states). Pressure fluctuations in drive systems caused by variable loading of operatind systems occur in the low frequency band, i.e. from 0.5 to $10 \mathrm{~Hz}$ (the infrasonic range), whereas the fluctuations originating from the pump are in a range of $50-1500 \mathrm{~Hz}$ (and above).

\section{Effective method of reducing low-frequency noise}

It is necessary to reduce low-frequency pressure fluctuations for ergonomic reasons and also because the reduction of the low-frequency excitations leads to minimization of the resonant vibration of the hydraulic system elements such as conduits, valves, controllers and distributors whose free vibration frequencies are in this frequency range. In order to minimize pressure fluctuation amplitudes in the low-frequency range, an active damper described in patent specification (Kudźma et al., 1991) has been adopted. Figure 4 shows this damper in its version adapted for laboratory testing. The adaptation consisted in the introduction of an additional piston rod making it possible to change the total mass of the vibrating system in a simple way.The low-frequency fluctuation damper shown in Fig. 4 works as follows (Kudźma and Stosiak, 2013; Kudźma, 2012). After cylinder 1 is filled with hydraulic oil and the hydropneumatic accumulator mounted in back cover 4 is pre-charged with nitrogen up to pressure $p_{0}$, the damper cylinder is connected in parallel through a threaded hole in back cover 5 to the pump pressure conduit. The damper operation comes down to the taking over of delivery fluctuations. The latter are the cause of the excitation of pressure fluctuations in the system. The excitations due to fluctuations in the delivery and, consequently, in pressure are taken over by the moving piston and piston rod-hydropneumatic spring system. Analysis of the mathematical model shows that the damper parameters are matched to ensure the equality of resonant frequency $f_{r}$ of the pistonhydropneumatic spring system and frequency $f_{w}$ of the excitation of pressure fluctuations in the system. The damper design enables the proper choice of its resonant frequency by changing reduced $M$ of the vibrating system, being the sum of piston mass $M_{t}$, mass $M_{c}$ of the liquid in the accumulator, the reduced-to-piston-surface mass of the liquid in the connector and a corrective mass mounted on a specially led out piston rod of the damper, in accordance with the relation 


$$
f_{r}=\frac{1}{2 \pi} \sqrt{\frac{n F_{0}^{2} p_{k}^{2}}{p_{0} V_{0} M}}
$$

where $F_{0}$ is the area of the piston active surface, $p_{k}$ - average operating pressure of the system, $p_{0}$ - initial pressure of the gas in the accumulator, $V_{0}$ - initial volume of the accumulator, $n$ - polytropic exponent.

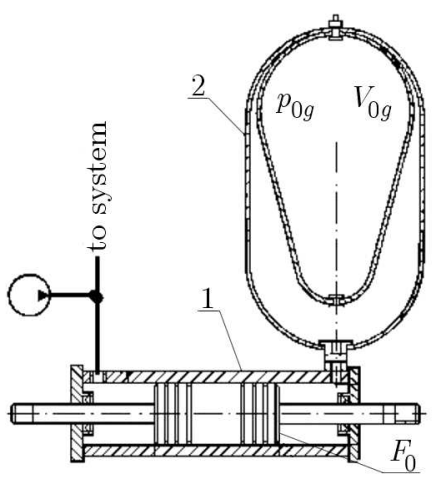

Fig. 4. Low-frequency active damper of pressure fluctuation in its laboratory version: 1 - cylinder, 2 - accumulator (Kudźma, 2012)

The damper effectiveness has been experimentally verified by determining the amplitudefrequency characteristic. The pressure fluctuation amplitude and the piston travel have been respectively the input quantity and the output quantity. In the course of the tests, the resonant frequency corresponding to the maximum transmittance has been determined, whereby an additional confirmation of the effectiveness of the active damper at the resonant frequency has been obtained (Fig. 5).

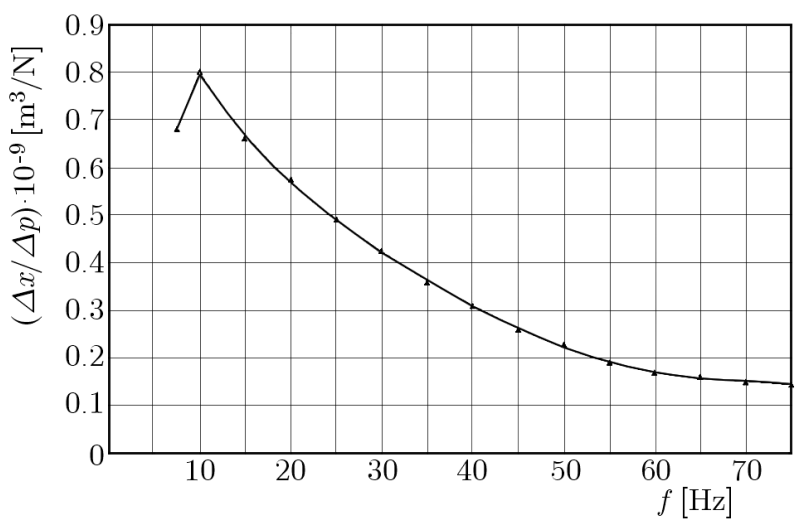

Fig. 5. Amplitude-frequency characteristic of the active damper with piston rod and HYDAC, accumulator, forcing pressure $12 \mathrm{MPa}$ (Kudźma, 2012); $\Delta p$ - amplitude of pressure fluctuation in the system with the active damper, $\Delta x$ - amplitude of displacement of the active damper piston caused by pressure fluctuation

\section{Experimental verification of damper effectiveness}

Hydraulic studies of pressure fluctuation, involving the low-frequency damper, have been carried out using a test rig designed by the author. The amplitude-frequency characteristics of the tested damper are determined. A pressure pulse exciter has been used to generate harmonic pressure fluctuations in a frequency range of $7-60 \mathrm{~Hz}$. The design and principle of operation of the exciter 
is presented in the paper by Kollek and Kudźma (1997). The test rig consisted of two main systems: a system generating harmonic pressure fluctuations and a feed system. The working medium, fed at a constant rate of delivery from the feed system, was subjected to harmonic pressure fluctuation excitations.

The low-frequency active damper has been installed shunt-wise relative to the main system. The damper has been supplied from the system via a connector situated under the piston, whereas above the piston the damper has been supplied from the accumulator $\left(p_{0}=2.2 \mathrm{MPa}\right.$, $\left.V_{0}=0.7 \mathrm{dm}^{3}\right)$. Exemplary results of the pressure fluctuation measurements are shown in Figs. 6-8.
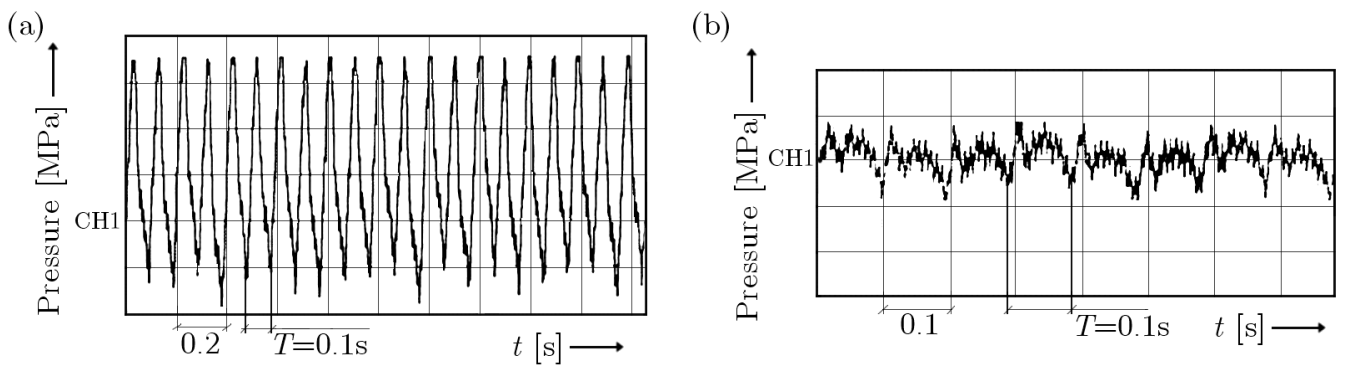

Fig. 6. Pressure fluctuation in the hydraulic system. Frequency of the pressure fluctuation excitation by the pulse exciter $f_{w}=10 \mathrm{~Hz}$, forcing pressure $p_{t}=16 \mathrm{MPa}$, (a) - system without the damper, (b) - system with the damper

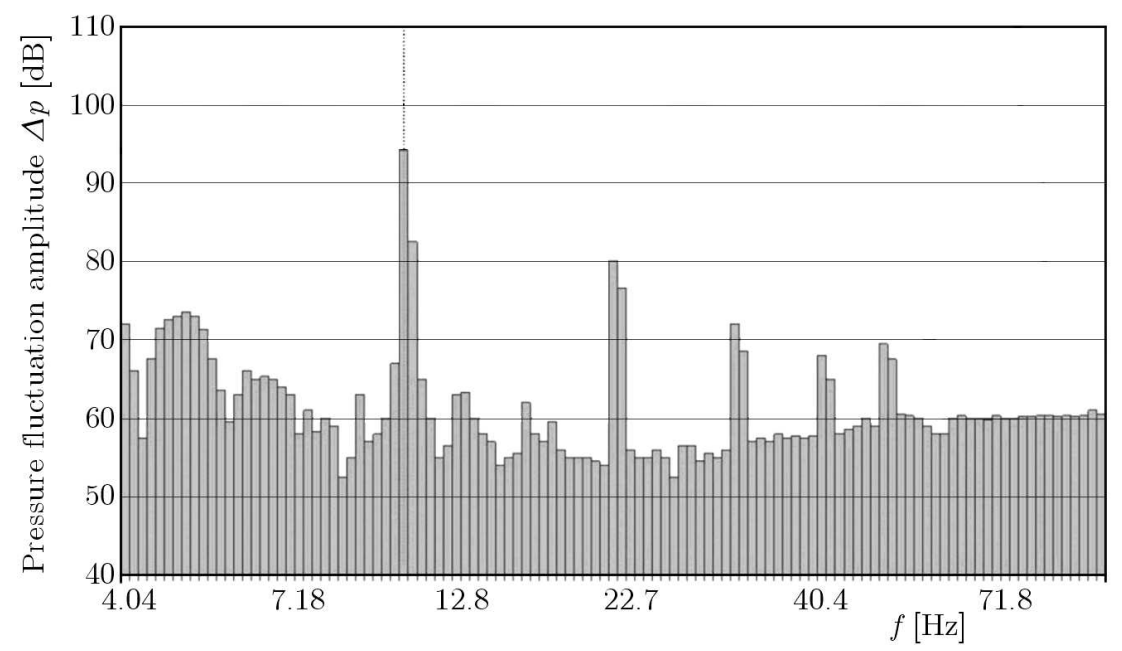

Fig. 7. Narrow-band spectrum of pressure fluctuations in the hydraulic system without the active damper. Frequency of the pressure fluctuation excitation by the pulse exciter $f_{w}=10 \mathrm{~Hz}$, forcing pressure $p_{t}=16 \mathrm{MPa}$

The above experimental results (Figs. 6a,b, 7 and 8) demonstrate the effectiveness of the low-frequency pressure fluctuation active damper in the infrasonic range.

\section{Discussion}

During operation of a hydrostatic drive system, a wide spectrum of excitations is generated (Kollek et al., 2007a,c). The latter, in turn, generate pressure fluctuations and, consequently, audible and infrasonic noise. Protection against infrasounds is difficult because of the considerable lengths of infrasonic waves $\left(\lambda_{f}=17-340 \mathrm{~m}\right)$ in the case of which the traditional walls, partitions, screens and sound absorbers are rather ineffective (Engel et al., 1999). Often infrasonic noise is 


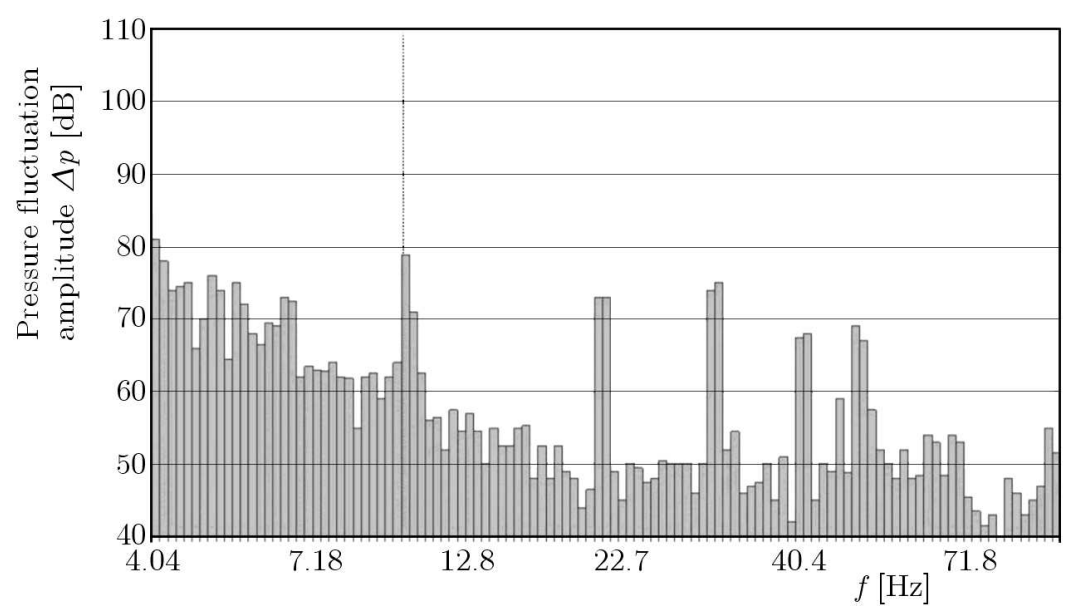

Fig. 8. Narrow-band spectrum of pressure fluctuations in the hydraulic system with the active damper. Frequency of the pressure fluctuation excitation by the pulse exciter $f_{w}=10 \mathrm{~Hz}$, forcing pressure

$$
p_{t}=16 \mathrm{MPa}
$$

amplified due to resonance of structural members of cabins and whole objects (Kaczmarska et al., 2000, 2006).

It is known from the measurement and operational practice related to machines with hydrostatic drives that in the pressure fluctuation spectrum, lower frequency (also infrasonic) components appear besides the components arising from the pump delivery fluctuations. This is due to external excitations and to dynamic properties of the hydraulic system connected with, among other things, resonance phenomena in the hydraulic conduits. One of the ways of reducing the impact of external low-frequency mechanical vibrations on the hydraulic valves is their flexible mounting. By mounting the valve housing flexibly (e.g. via a pack of springs) and by matching the ratio of the spring stiffness to the valve mass with the frequency which is to be reduced, a reduction in vibrations of the pump casing in the low frequency range close to the resonance of the control element, e.g. a distributor slide (Fig. 9) can be obtained.

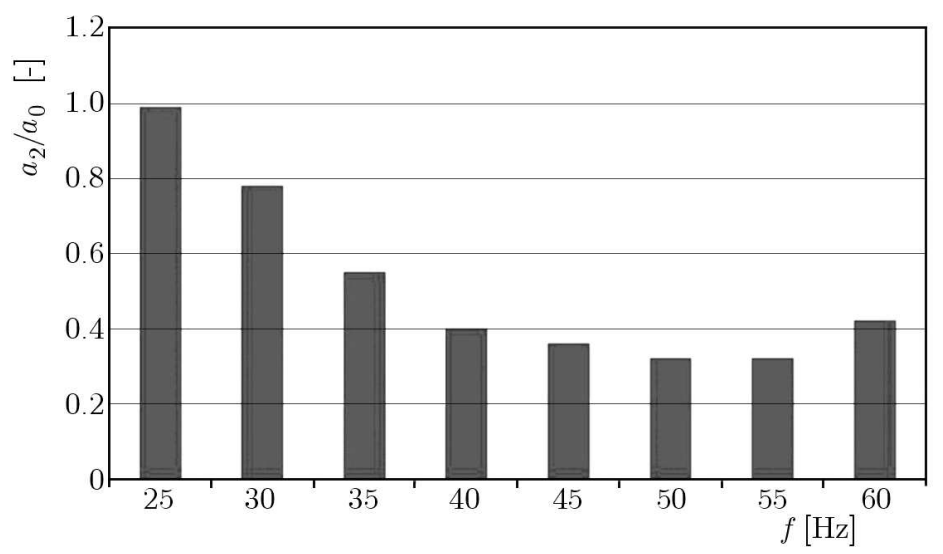

Fig. 9. Transmission function $a_{2} / a_{0}$ for the housing of the proportional distributor for $f=25-60 \mathrm{~Hz}$

It appears from the diagram shown in Fig. 9 that for a system of springs with equivalent stiffness $c_{z}=86000 \mathrm{~N} / \mathrm{m}$ and a proportional distributor with mass of $4.5 \mathrm{~kg}$, the vibration insulation is effective (transmission function $a_{2} / a_{0}<1$ ) in the given external vibration frequency range. As a result of the insulation, the distributor housing vibration amplitude and the distributor slide-valve vibration amplitude decrease (Stosiak, 2006b). Consequently, the amplitude of the pressure fluctuations due to the excitation of distributor slide-valve vibrations also decre- 
ases. However, in the case of so simple vibration insulation, the resonance may be generated at external vibration frequencies other than those used in the test. Therefore, a vibration insulating element with other properties and characteristics, e.g. with nonlinear stiffness and with damping made of elastomers, should be used. An example of an elastomer washer used as a vibration insulatingelementis shown in Fig. 10. This element has been tested ina wide range of frequencies. Theoretical considerations related to vibration insulation for hydraulic valves were presented in detail by Stosiak (2011).

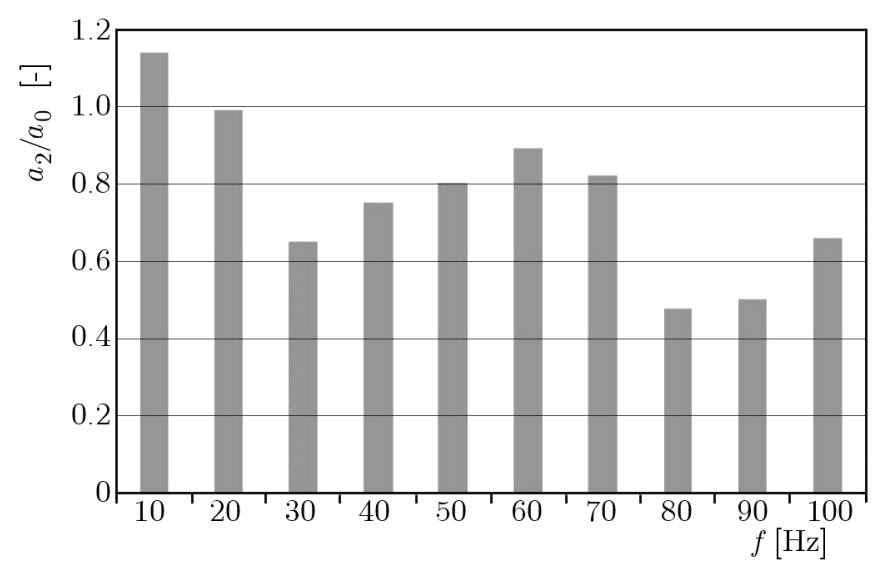

Fig. 10. Vibration acceleration amplitude $a_{2}$ of the proportional distributor housing relative to the excitation vibration acceleration amplitude $a_{0}$ for $f=10-100 \mathrm{~Hz}$

The problem of reduction of vibrations of the valve housing can be focused on analysis of dynamic behavior of the system presented in Fig. 11.

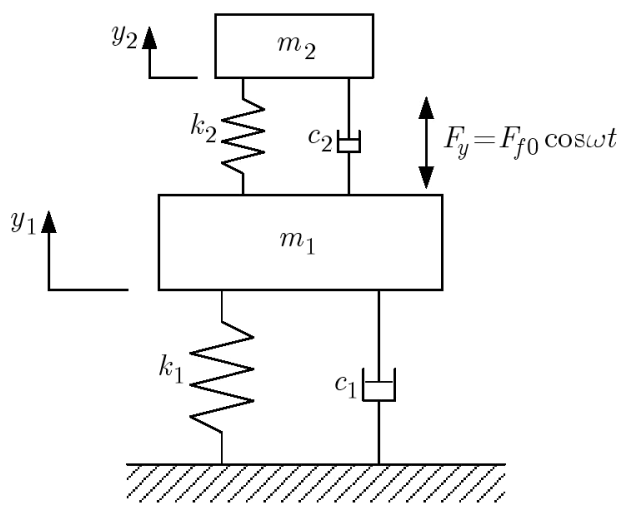

Fig. 11. Scheme of the hydraulic distributor mounted on a flexible base: $m_{1}$ - distributor housing, $m_{2}$ - slide

Vibration of the distributor housing excited by force the $F_{y}$ can be described by equations (Goliński, 1979)

$$
\begin{aligned}
& m_{1} \ddot{y}_{1}+c_{1} \dot{y}_{1}+k_{1} y_{1}+c_{2}\left(\dot{y}_{1}-\dot{y}_{2}\right)+k_{2}\left(y_{1}-y_{2}\right)=F_{f 0} \cos \omega t \\
& m_{2} \ddot{y}_{2}+c_{2}\left(\dot{y}_{2}-\dot{y}_{1}\right)+k_{2}\left(y_{2}-y_{1}\right)=0
\end{aligned}
$$

where $m_{1}$ is mass of the housing, $c_{1}$ - equivalent damping of the flexible base, $k_{1}$ - equivalent stiffness of the flexible base (e.g. set of elastomers), $c_{2}$ - slide-sleeve damping, $k_{2}$ - equivalent spring stiffness in the slide-sleeve system, $y_{1}$ - housing displacement, $y_{2}$ - slide displacement.

In equation $(6.1)_{1}$, the model of the flexible base is described by the Kelvin-Voigt model (stiffness $k_{1}$ and damping $c_{1}$ ). 
The solution for steady vibrations is determined by equations

$$
y_{1}=y_{01} \cos \left(\omega t-\varphi_{1}\right) \quad y_{2}=y_{02} \cos \left(\omega t-\varphi_{2}\right)
$$

where

$$
\tan \varphi_{1}=\frac{A_{1} D-B_{1} C}{A_{1} C+B_{1} D} \quad \tan \varphi_{2}=\frac{A_{2} D-B_{2} C}{A_{2} C+B_{2} D}
$$

The amplitudes of steady vibrations $y_{01}$ and $y_{02}$ can be found from equations

$$
y_{01}=\frac{F_{f 0}\left(\frac{\omega_{1}}{\omega_{2}}\right)^{2}}{m_{1} \omega_{1}^{2}} \sqrt{\frac{A_{1}^{2}+B_{1}^{2}}{C^{2}+D^{2}}} \quad y_{02}=\frac{F_{f 0}\left(\frac{\omega_{1}}{\omega_{2}}\right)^{2}}{m_{1} \omega_{1}^{2}} \sqrt{\frac{A_{2}^{2}+B_{2}^{2}}{C^{2}+D^{2}}}
$$

where

$$
\begin{aligned}
& A_{1}=1-\left(\frac{\omega}{\omega_{2}}\right)^{2} \quad B_{1}=\frac{c_{2} \omega}{m_{2} \omega_{2}^{2}} \quad A_{2}=1 \quad B_{2}=B_{1} \\
& C=\left[\left(\frac{\omega_{1}}{\omega_{2}}\right)^{2}-\left(\frac{\omega}{\omega_{2}}\right)^{2}+\frac{m_{2}}{m_{1}}\right]\left[1-\left(\frac{\omega}{\omega_{2}}\right)^{2}\right]-\frac{m_{2}}{m_{1}}-\frac{c_{1} c_{2} \omega^{2}}{m_{1} m_{2} \omega_{1} \omega_{2}^{3}} \\
& D=2 \frac{\omega \omega_{1}}{\omega_{2}^{2}}\left(\frac{c_{1}}{2 m_{1} \omega_{1}}+\frac{c_{2} \omega_{1}}{2 m_{2} \omega_{2}^{2}}\right)-2\left[\frac{c_{1}}{2 m_{1} \omega_{2}}+\left(1+\frac{m_{2}}{m_{1}}\right) \frac{c_{2}}{2 m_{2} \omega_{2}}\right]\left(\frac{\omega}{\omega_{2}}\right)^{3} \\
& \omega_{1}=\sqrt{\frac{k_{1}}{m_{1}}} \quad \omega_{2}=\sqrt{\frac{k_{2}}{m_{2}}}
\end{aligned}
$$

In order to reduce housing vibrations, the amplitude of steady vibrations given by equation $(6.4)_{1}$ should be reduced by application of a vibroisolator with proper stiffness and damping. Figure 12 presents an exemplary course of the amplitude of housing steady vibrations for selected parameters of equation $(6.4)_{1}: m_{1}=4.5 \mathrm{~kg}, m_{2}=0.18 \mathrm{~kg}, k_{2}=5800 \mathrm{~N} / \mathrm{m}, c_{2}=12 \mathrm{~kg} / \mathrm{s}$, $\omega=251 \mathrm{rad} / \mathrm{s}, F_{f 0}=187 \mathrm{~N}$.

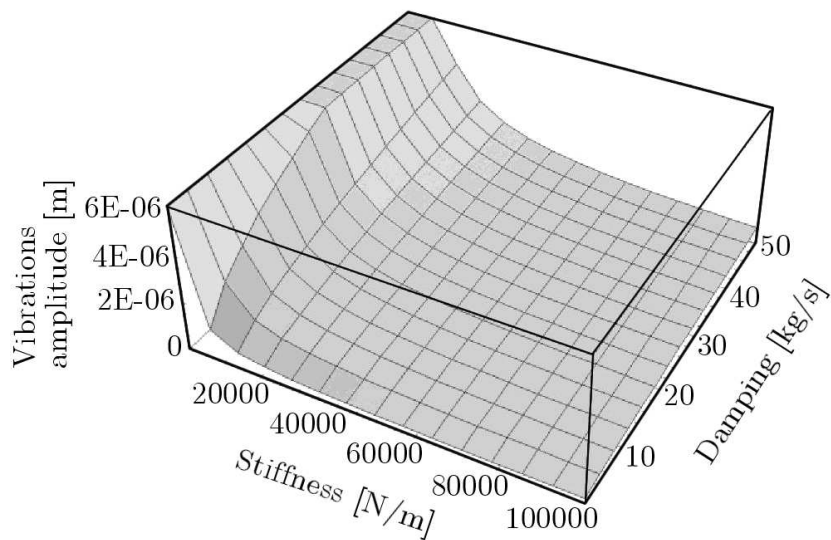

Fig. 12. Amplitude of housing steady vibrations in function of vibroisolator stiffness and damping

Reduction in valve housing vibration will lead to reduction in slide-valve vibration, particularly in the resonant vibration range. As a result, the pressure fluctuations and the emitted noise (particularly in a low frequency range) will decrease, and the precision of motions of the hydraulic receivers will increase. Vibration insulators in such applications should also satisfy other criteria, such as resistance to changes in ambient temperature, resistance to hydraulic fluids and small geometric dimensions. Therefore, besides having proper physicochemical properties, the vibration insulator should have a standardized design suitable for typical connection plates for hydraulic valves. 


\section{Conclusion}

The dangers connected with the occurrence and impact of low-frequency vibrations and as well as noise in hydraulic systems have been presented. The problem is important because of particularly harmful effects of such excitations on the human body. This is reflected in the standards concerning the introduction of machines and equipment incorporating hydraulic systems into the EU markets.

The special focus has been put on the reduction of noise emitted by heavy engineering machines, taking into account especially infrasonic noise and, generally, low-frequency noise. It is indicated that the hydrostatic drive system is one of the main noise sources in engineering machines. Sounds are generated as a result of pressure fluctuations. The effectiveness of a lowfrequency damper has been experimentally tested in the process of reducing pressure fluctuation amplitudes. The damper has been found to be most effective when its free frequency coincided with the excitation frequency to be reduced.

\section{References}

1. Bryan M., 1972, Infrasounds and drivers (in Polish), Problemy, 11, 45-48

2. Cichoń P., Stosiak M., 2011, Simulator of linear hydrostatic drive in hydraulic laboratory (in Polish), Napędy i Sterowanie, 11, 112-117

3. Directive 98/37/EC of the European Parliament and of the Council of 22 June 1998 on the approximation of the laws of the Member States relating to machinery

4. Directive 2000/14/EC of the European Parliament and of the Council of 8 May 2000 on the approximation of the laws of the Member States relating to the noise emission in the environment by equipment for use outdoors

5. Engel Z., Sikora J., Turkiewicz J., 1999, Integrated acoustical-insulating enclosures (in Polish), Bezpieczeństwo Pracy, Nauka i Praktyka, 1, 2-8

6. Engel Z., ZaWieska W., 2010, Noise and Vibration in Work Processes - Sources, Assessment, Hazards (in Polish), Warsaw

7. Goliński J., 1979, Vibroisolation of Machines and Devices (in Polish), Wydawnictwo NaukowoTechniczne, Warszawa

8. Grajnert J., 1997, Vibration Insulation in Machines and Vehicles (in Polish), Wrocław University of Technology Publishing House, Wrocław

9. Kaczmarska A., Augustyńska D., Engel Z., 2000, Resonator structures reducing low-frequency noise in industrial cabins (in Polish), Bezpieczeństwo Pracy, Nauka i Praktyka, 11, $14-16$

10. Kaczmarska A., Augustyńska D., Wierzejski A., 2006, Infrasonicnoise in driver work place (in Polish), Bezpieczeństwo Pracy, 10, 6-8

11. Kollek W., Kudźma Z., 1997, Passive und aktive Metoden der Druckpulsation und Larminderung in Hydrostatischen Systemen, Innovation und Fortschritt in der Fluidtechnik, Zweites Deutsch-Polnisches Seminar, Technische Universität Warszawa, Fakultat für Mechatronik, 276-294

12. Kollek W., Kudźma Z., Mackiewicz J., Stosiak M., 2007a, Possibilities of diagnosing cavitation in hydraulic systems, Archives of Civil and Mechanical Engineering, 7, 1, 61-73

13. Kollek W., Kudźma Z., Rutański J., Stosiak M., 2007b, Reduction of low- and high-frequency noise in hydrostatic systems (in Polish), Przeglad Mechaniczny, 4, 26-30

14. Kollek W., Kudźma Z., Stosiak M., 2007c, Identification of pressure fluctuations in hydraulic system (in Polish), Hydraulic and Pneumatic Drives and Controls, International Scientific- Technical Conference, Wrocław 10-12 October 2007, SIMP Personnel Training Centre, 205-217 
15. Kollek W., Kudźma Z., Stosiak M., 2008, Propagation of vibrations of heavy engineering machine's load-bearing components (in Polish), Transport Przemysłowy i Maszyny Robocze, 2, $50-53$

16. Krylov V., Pickup S., McNuff J., 2010, Calculation of ground vibration spectra from heavy military vehicles, Journal of Sound and Vibration, 329, 115, 3020-3029

17. Kudźma Z., 1990, Frequency of free vibration of pressure relief valve and hydraulic system (in Polish), Sterowanie i Naped Hydrauliczny, 3, 4-8

18. Kudźma Z., 2012, Pressure Fluctuation and Noise Damping in Hydraulic Systems in Transient and Steady States (in Polish), Wrocław University of Technology Publishing House, Wrocław

19. Kudźma Z., Kollek W., Rutański J., 1991, Active damper of pressure fluctuations (in Polish), Patent specification PL 165398

20. Kudźma Z., Stosiak M., 2013, Reduction of infrasounds in machines with hydrostatic drive, Acta of Bioengineering and Biomechanics, 15, 2, 51-64

21. LeEa E. C., Nianb C.Y., TARng Y.S., 2001, Design of a dynamic vibration absorber against vibrations in turning operations, Journal of Materials Processing Technology, 108, 278-285

22. Leventhall H.,G., 1973, Man-made infrasound. Its occurrence and some subjective effects, Proceedings of 20th Open Seminar on Acoustics, Poznań, 3, 21-38

23. Malsev E.N., 1974, On the effect of infrasound on the human body (in Russian), Gigiena $i$ Sanitarija, 3, 27-30

24. Ministry of Labour and Social Policy Order of 29 November 2002 concerning the highest permissible concentrations and intensities of harmful factors in work environment (in Polish), Law Gazette, 217, 1833

25. Misra A., Behdinan K., Cleghorn W.L., 2002, Self-excited vibration of a control valve due to fluid-structure interaction, Journal of Fluids and Structures, 5, 649-665

26. Pawlaczyk-Łuszczyńska M., Augustyńska D., Kaczmarska A., 2001, Infrasonic noise. Measuring Procedure. Documentation of proposed values of permissible occupational hazard levels (in Polish), Podstawy $i$ Metody Oceny Środowiska Pracy, XVII, 2, 28

27. Pytlik A., 2008, Vibrations in hydraulic systems of mechanized casing section (in Polish), Napeddy i Sterowanie, 10, 4, 121-130

28. PN-ISO 7196:2002 Acoustics - Frequency characteristics of filter for measuring infrasounds (in Polish)

29. PN-ISO 9612:2004 Acoustics - Principles of measuring and evaluating noise exposure in work environment (in Polish)

30. Renowski J., 1988, Noise: Indices and Evaluation Criteria (in Polish), Wrocław University of Technology Publishing House, Wrocław

31. Stosiak M., 2006a, Effect of mechanical vibrations of foundation on pressure fluctuation in hydraulic system (in Polish), Hydraulika i Pneumatyka, 3, 5-8

32. Stosiak M., 2006b, The effect of the low-frequency mechanical vibrations of the base on the control component of the hydraulic valve (in Polish), [In:] Rozwój maszyn i urzadzeń hydraulicznych, Wacław Kollek (Edit.), Wrocław, Wydawnictwo Wrocławskiej Rady FSNT NOT, 11, 2/3, 83-94

33. Stosiak M., 2011, Vibration insulation of hydraulic system control components, Archives of Civil and Mechanical Engineering, 11, 1, 237-248

34. TABACZEK T., Zawiślak M., Zieliński A., 2012, Calculation of flow with cavitation in centrifugal pump (in Polish), Systems: Journal of Transdisciplinary Systems Science, 16, 2, 385-394

35. Tomasiak E., 1983, Selected problems of valve dynamics (in Polish), Sterowanie $i$ Naped Hydrauliczny, 6, 8-12 